\title{
Effects on health of a change from a delaying to an advancing shift system
}

\author{
J Barton, S Folkard, L Smith, C J M Poole
}

\begin{abstract}
Objectives-Shift work can lead to a range of problems for some people that seem to result from the disturbance of the circadian system, and can broadly be classified as: disturbances of sleep, impaired physical and psychological health, and disturbed social and domestic life. The main attempt to try to reduce these problems has focused on the design of the shift system, and the identification of the most problematic features of the shift system. One such feature is believed to be the direction of shift rotation. Systems that advance are thought to be more problematic than those that delay. The present study examines the change in the direction of shift rotation from a delaying to an advancing system on health and wellbeing.
\end{abstract}

Methods-Self reported measures of tolerance to shift work were taken two months before and six months after the change. These included sleep difficulties, gastrointestinal problems, psychological ill health, chronic fatigue, social and domestic disruption, job satisfaction, and satisfaction with the shift system.

Results-The change from a delaying to an advancing system resulted in an increase in sleep difficulties between successive afternoon shifts, but a decrease in social disruption. There was little evidence of impaired health on the advancing compared with the delaying system. Conclusions-The increase in sleep difficulties was thought to result from the undesired adaptation of the circadian system to night work, as a result of the afternoon shifts now following a series of night shifts, whereas previously they followed a series of morning shifts. The decrease in social disruption was thought to result from the specific sequence of the shifts and the discontinuous nature of the shift system, in particular, the long weekend off every third week. Lack of reported health related differences are explained in terms of the relatively unharmful nature of the shift system in question, and the relatively short time span over which the study was conducted.

(Occup Environ Med 1994;51:749-755)

Keywords: shift rotation, advancing, delaying.

There is a generally accepted view that shift work may lead to a range of problems for many people. These problems fall broadly into three categories: physical and psychological health, ${ }^{1-5}$ social and domestic disruption, ${ }^{67}$ and sleep disturbances and fatigue..$^{2-11}$ One approach to try to reduce these problems has focused on the design of the shift system. Certain aspects of the shift system are thought to be more problematic for the people concerned than others. Thus, much research has focused on trying to identify those featuresfor example, the number of successive night shifts worked ${ }^{12}$ and the flexibility of the shift system. ${ }^{13}$ It has been argued that the design of shift systems ought to take into account the principles of the circadian system $^{14}$-for example, the fact that in the absence of external time cues, the sleep-wake cycle runs with a period of about 25 hours, so that sleep "naturally" occurs later and later with respect to clock time. ${ }^{15}$ Thus, this delaying tendency of the sleep-wake rhythm may make it easier for people to stay awake longer than to fall asleep earlier than normal. Consequently, it has been argued that shift systems that rotate should do so by successive phase delays - that is, from mornings to afternoons to nights - rather than successive phase advances-that is, from nights to afternoons to mornings.

A second, and equally important reason why systems that delay may be preferable to those that advance, relates to the amount of time off between shifts. Systems that delay always incorporate a break of 24 hours (or multiples thereof) when changing from one type of shift to another. Shifts that advance need only incorporate a break of eight hours (or eight plus whole number multiples of 24). Social pressures often result in only an eight hour break being scheduled so that time off can be accumulated into occasional longer breaks at the end of a sequence of shifts, for example at a weekend. These "quick returns" from one shift to another after only an eight hour break may severely restrict sleep duration and exacerbate the shift workers' problems, despite their popularity because of periodic extended breaks away from work.

Studies that have looked specifically at the impact of the direction of shift rotation on the individual shift workers are few. One study, with a sample of 46 policemen (23 in each of two groups) used a crossover design where each worker acted as his own control. ${ }^{16}$ Both groups worked for four weeks rotating in each direction, with one group delaying first and the other group advancing first. Overall, there seemed to be fewer physical, social, and psychological problems experienced on delaying systems compared with advancing. Another 
study, ${ }^{17}$ with a group of 22 microelectronic workers, found that workers went to sleep earlier after a night shift and an afternoon shift, and reported improved variables of sleep quality in general, after the change from advancing to delaying shifts. Thus, it has been argued that from a biological point of view, systems that delay permit a quicker adaptation, particularly of sleep times, than systems that advance. ${ }^{18}$ Workers on delaying systems went to sleep earlier after a night or an afternoon shift than workers on advancing systems. Those on delaying systems cited improved sleep after both shifts as the main reasons for preferring that schedule. Of interest also was the increased difficulty in falling asleep after an afternoon shift on the advancing system. More recently a study that involved over 300 industrial shift workers on a range of advancing and delaying continuous systems found relatively small differences, yet consistently fewer problems, to be associated with delaying as opposed to advancing systems that did not include a quick return. ${ }^{19}$ Better physical and psychological health, less chronic fatigue, less social and domestic disruption, fewer sleep difficulties, and more job satisfaction were reported by workers on delaying systems. Also, the presence of a quick return was found to exacerbate the problems of those on advancing systems.

The small differences found between advancing systems without a quick return and delaying systems may partly be explained by the arguments of Turek. ${ }^{20}$ Even though the time of the work period might be delayed, the time of sleep onset need not necessarily be so. There may be little difference in the time of sleep onset before a morning or an afternoon shift, on either an advancing or a delaying system, as people do have a choice as to when they go to sleep. ${ }^{20}$ Sleep onset has been shown to be linked closely to what has been termed a "sleep gate"- that is, a sudden and dramatic increase in sleep propensity, believed to occur between 2100 and $0400 .^{21}$ The time immediately preceding the sleep gate has been termed the "forbidden zone" for sleep-that is, a period lasting for around four hours during which sleep propensity is greatly reduced. ${ }^{22}$ From the point of view of the body clock, the time of sleep onset will depend largely on the presence of the forbidden zone, and may be less influenced by the direction of shift rotation. As such, sleep onset before a morning or afternoon shift may not differ greatly on either an advancing or a delaying system. Consequently, the more important factor might be the presence of a quick return, a view that would support some of the most recent findings. ${ }^{19}$

A potential study arose when a change in shift system was imposed on a group of 3000 car manufacturing employees. Two discontinuous shift systems were in operation, one delayed and the other advanced. For the purpose of consistency it was decided by management to change all shift workers on delaying to advancing shifts. The present study therefore examined the effects of this change in the direction of shift rotation on the health and wellbeing of a sample of those involved. Two hypotheses were tested.

(1) Workers on the advancing system would report poorer health and lower levels of wellbeing than workers on the delaying system, and both would show more problems than the day workers.

(2) The workers who changed from a delaying to an advancing system would report an increase in ill health and lower levels of wellbeing.

\section{Method}

DESIGN AND CONTEXT

The study was longitudinal with a before and after test design. Data were collected by means of a self reported questionnaire two months before (time 1) and six months after (time 2) the change. Three groups of workers participated: an experimental three shift group who changed from a delaying to an advancing system, and two non-equivalent control groups: firstly, a group of workers on three shifts who remained on an advancing system (control three shift); secondly, a group of day workers who did not work shifts (control day). At the time of the first data collection none of the three shift workers were aware of which system was subsequently to change.

We acknowledge the relatively short time period over which the study was conducted, yet other studies that involved shift system changes have used a similar follow up period $^{53-25}$ or less. ${ }^{16}$ The main advantage of the design of this study was the inclusion of two control groups. It has been noted that it is rare to find longitudinal designs in shift work studies, ${ }^{26}$ and even more rare to find shift work studies that have used a control group. ${ }^{24}$

SHIFT SYSTEMS

The shift (and day) systems were discontinuous, and did not involve weekend work. The number and times of shifts were the same for the experimental and control three shift groups: one week of morning shifts (Monday to Friday), one week of afternoon shifts (Monday to Friday), and one week of night shifts (Monday to Thursday). Thus, the advancing system did not include any quick returns. All shifts were eight hours duration: 0600-1400, 1400-2200 and 2200-0600; except for those on Friday, the morning shift lasted from 0600-1200, and the afternoon shift from 1200-1800 at which point the production stopped for the weekend. The shifts worked by the control three shift group (advancing) rotated in a backward direction (night to afternoon to morning), whereas those worked by the experimental group (delaying) rotated in a forward direction (morning to afternoon to night). Consequently, the main difference between the two three shift systems was the direction of rotation and the variability in the length of breaks at the weekend. Those on the advancing system had a longer than usual weekend break when changing from morning to night shifts 
(82 hours), and when changing from night to afternoon shifts ( 80 hours). However, the change from afternoon to morning shifts resulted in a break considerably shorter (60 hours) than any of the breaks associated with the delaying system. These were: morning to afternoon shifts ( 74 hours), afternoon to night shifts (76 hours) and night to morning shifts (72 hours). The work times of the control (day) group were 0830-1630 Monday to Thursday, and 0830-1330 on Friday.

\section{PARTICIPANTS}

A total of 363 people took part in the study, 120 in the experimental group, 173 in the control three shift group, and 70 in the control day group. Table 1 shows the demographic details of the three groups. Of these, $248(68 \%)$ took part in the second stage of the study; $92(77 \%)$ of the experimental group, $121(70 \%)$ of the control three shift group, and $35(50 \%)$ of the control day workers. Those who did not take part at time 2 had either changed to another shift system, had not provided any means of identification, or had left the company altogether. At time 1 there was no difference in age $\left(F_{1,288}\right)=0 \cdot 00$, $\mathrm{P}>0.05)$ or experience of shiftwork $\left(F_{1,287}\right)=$ $0.00, P>0.05)$ between the experimental and the control three shift groups, although the control day workers were significantly older $\left.\left(F_{2,357}\right)=26.62, \mathrm{P}<0.001\right)$ and had spent significantly more years on day only work than the shift workers had spent on shift work $\left.\left(F_{2,330}\right)=19.73, \mathrm{P}<0.001\right)$. There were predominantly more men than women in the study, although the distribution was more even within the control day group than within the other two groups.

\section{MEASURES}

The measures included in the questionnaire were chosen to cover the main problems commonly reported by shift workers. All the scales were taken from, or derived from the standard shift work index (SSI), ${ }^{27}$ which is a battery of questionnaires for assessing the impact of different types of shift systems on the health and wellbeing of large groups of shift workers. For a full description of the measures see Barton et al. ${ }^{28}$ All the scales have previously been used in shift work studies, most of which have been shown to be sensitive to the impact of shift work and to various features of shift systems, including the direction of shift rotation..$^{1319}$ On each of the measures a higher score was associated with the experience of more of a problem or more dissatisfaction.

\section{Table 1 Demographic data}

\begin{tabular}{llcc}
\hline & $\begin{array}{l}\text { Control (3 shift) } \\
(n=173)\end{array}$ & $\begin{array}{l}\text { Experimental } \\
(n=120)\end{array}$ & $\begin{array}{c}\text { Control (day) } \\
(n=70)\end{array}$ \\
\hline Men & 159 & 112 & 56 \\
Women & 14 & 8 & 14 \\
Mean (SD) age & $30 \cdot 16(7 \cdot 46)$ & $30 \cdot 14(8 \cdot 09)$ & $38 \cdot 54(11 \cdot 50)$ \\
Married (\%) & $67 \cdot 1$ & $67 \cdot 5$ & $68 \cdot 6$ \\
Separated or divorced (\%) & $2 \cdot 3$ & $4 \cdot 29$ & $8 \cdot 6$ \\
Widowed (\%) & $30 \cdot 6$ & $28 \cdot 3$ & $1 \cdot 4$ \\
Single (\%) & $0 \cdot 93$ & $1 \cdot 16$ & $21 \cdot 4$ \\
Children & $3 \cdot 80(4 \cdot 60)$ & $3 \cdot 83(4 \cdot 33)$ & $0 \cdot 87$ \\
Mean (SD) years in shift work & & & $9 \cdot 14(8 \cdot 53)$ \\
\hline
\end{tabular}

Psychological wellbeing questionnaire (GHQ-12) ${ }^{29}$ The psychological wellbeing questionnaire is a standardised, self administered screening test to detect psychiatric morbidity in the general population. It gives an estimate of mental health over the previous few weeks, ${ }^{30}$ and can be used to assess the degree of psychiatric morbidity. For this study, high and low scorers on the questionnaire were identified, high being three or more, as scores of this magnitude are most likely to be associated with psychiatric morbidity. ${ }^{31}$

\section{Chronic fatigue}

Chronic fatigue is measured by a 10 item self reported questionnaire, intended to give a measure of the chronic tiredness experienced by shift workers, which persists even on rest days and holidays.

\section{Gastrointestinal symptoms}

A five item self reported measure of gastrointestinal symptoms was used.

Sleep quality and difficulties

We used a four item measure of sleep quality associated with morning, afternoon, and night shifts, and rest days.

\section{Sleep record}

Usual sleep onset and wake up times associated with morning, afternoon, and night shifts, and with rest days were recorded. From these it was possible to calculate average sleep durations.

\section{Social and domestic disruption}

We used three items that scored on a five point Likert scale, measuring the amount of social and domestic disruption experienced, and two items that rated satisfaction with social life and sex life.

\section{Work and shift satisfaction}

A five item measure of general job satisfaction, part of the larger job diagnostic survey was used, ${ }^{32}$ and two individual items were included: one relating to enjoyment at work, and the other to shift system satisfaction.

\section{Demographic and general information}

Questions relating to sex, age, marital status, number of children, and years of work experience were included. Also, there were two questions that asked about the number of cigarettes smoked and the number of units of alcohol consumed a week.

\section{PROCEDURE}

Individual workers while at work were approached by the researchers and asked to take part in the study. It was explained that the researchers would be returning in eight months to conduct a follow up study. The questionnaires were completed during the workers' break time, and handed back to the researcher the same day. Workers were asked to put either their name or identification code number at the top of the questionnaire, so that they could be traced in eight months time. Participation was entirely voluntary. 
Table 2 Differences between the mean scores for the groups at time 1

\begin{tabular}{|c|c|c|c|c|c|c|}
\hline & $\begin{array}{l}\text { A } \\
\text { Control } \\
\text { three shift } \\
\text { Advance } \\
(n=173)\end{array}$ & $\begin{array}{l}B \\
\text { Experimental } \\
\text { Delay } \\
(n=120)\end{array}$ & $\begin{array}{l}\text { Control day } \\
(n=70)\end{array}$ & $D f$ & $F$ & \\
\hline Psychological health & 11.63 & $11 \cdot 35$ & $11 \cdot 08$ & 2,212 & $0 \cdot 15$ & $\mathrm{~A}, \mathrm{~B}, \mathrm{C}$ \\
\hline Chronic fatigue & 27.97 & 28.01 & $26 \cdot 35$ & 2,191 & $0 \cdot 29$ & $\mathrm{~B}, \mathrm{~A}, \mathrm{C}$ \\
\hline Gastrointestinal problems & $9 \cdot 43$ & $8 \cdot 89$ & $8 \cdot 10$ & 2,216 & $1 \cdot 88$ & $\mathrm{~A}, \mathrm{~B}, \mathrm{C}$ \\
\hline Social disruption & 3.65 & $3 \cdot 36$ & $2 \cdot 21$ & 2,232 & $13 \cdot 19^{\star \star \star}$ & $\mathrm{A}, \mathrm{B}>\mathrm{C}$ \\
\hline Domestic disruption & $3 \cdot 14$ & $2 \cdot 90$ & 1.90 & 2,232 & $7 \cdot 48^{\star \star \star}$ & $\mathrm{A}, \mathrm{B}>\mathrm{C}$ \\
\hline Non-domestic disruption & 2.45 & $2 \cdot 37$ & 1.88 & 2,227 & 1.89 & $\mathrm{~A}, \mathrm{~B}, \mathrm{C}$ \\
\hline Social life dissatisfaction & 3.23 & $2 \cdot 83$ & 1.90 & 2,231 & $10.96^{\star \star \star}$ & $\mathrm{A}>\mathrm{B}>\mathrm{C}$ \\
\hline Sex life dissatisfaction & $2 \cdot 38$ & $2 \cdot 18$ & $2 \cdot 13$ & 2,222 & 0.76 & $\mathrm{~A}, \mathrm{~B}, \mathrm{C}$ \\
\hline Job dissatisfaction & $18 \cdot 57$ & $19 \cdot 23$ & $18 \cdot 18$ & 2,210 & 0.39 & B,A,C \\
\hline Lack of enjoyment at work & $3 \cdot 11$ & 3.49 & 3.56 & 2,234 & $3 \cdot 26^{\star}$ & \\
\hline Shift system dissatisfaction & $3 \cdot 21$ & 2.94 & 1.81 & 2,222 & $21 \cdot 08^{\star \star \star}$ & $\mathrm{A}>\mathrm{B}, \mathrm{C}$ \\
\hline Alcohol consumption & 8.53 & $9 \cdot 88$ & $8 \cdot 83$ & 2,220 & 0.49 & $\mathrm{~B}, \mathrm{C}, \mathrm{A}$ \\
\hline Cigarette consumption & $44 \cdot 68$ & $49 \cdot 85$ & $22 \cdot 79$ & 2,218 & 1.62 & B,A,C \\
\hline \multicolumn{7}{|l|}{ Sleep difficulties between: } \\
\hline Morning shifts & $\begin{array}{l}10 \cdot 75 \\
10 \cdot 28\end{array}$ & $\begin{array}{r}11 \cdot 34 \\
0.01\end{array}$ & $8 \cdot 80$ & 2,201 & $\begin{array}{l}2 \cdot 29 \\
8 \cdot 29 \star \star \star\end{array}$ & $\underset{A>B}{B, A, C}$ \\
\hline $\begin{array}{l}\text { Afternoon shifts } \\
\text { Night shifts }\end{array}$ & $\begin{array}{l}10 \cdot 28 \\
10 \cdot 11\end{array}$ & $\begin{array}{r}9 \cdot 01 \\
10 \cdot 36\end{array}$ & & $\begin{array}{l}1,190 \\
1,187\end{array}$ & $\begin{array}{l}8 \cdot 29 \times \pi x \\
0 \cdot 21\end{array}$ & $\begin{array}{l}A>B \\
A, B\end{array}$ \\
\hline Rest days & 8.99 & $8 \cdot 83$ & $9 \cdot 45$ & 2,177 & $0 \cdot 17$ & C,A,B \\
\hline \multicolumn{7}{|l|}{ Sleep duration between: } \\
\hline Morning shifts & $5 \cdot 88$ & $6 \cdot 04$ & $7 \cdot 58$ & 2,191 & $6 \cdot 94^{\star \star \star}$ & $\mathrm{C}>\mathrm{B}, \mathrm{A}$ \\
\hline Afternoon shifts & $8 \cdot 57$ & $8 \cdot 62$ & & 1,176 & 0.05 & \\
\hline Night shifts & $7 \cdot 51$ & $7 \cdot 40$ & & 1,185 & $0 \cdot 22$ & $\mathbf{A}, \mathbf{B}$ \\
\hline Rest days & $8 \cdot 74$ & $8 \cdot 98$ & $8 \cdot 78$ & 2,166 & 0.58 & $\mathrm{~B}, \mathrm{C}, \mathrm{A}$ \\
\hline \multicolumn{7}{|l|}{ Sleep onset between: } \\
\hline Morning shifts & $22 \cdot 37$ & $22 \cdot 28$ & $23 \cdot 16$ & 2,310 & $5 \cdot 69^{\star \star}$ & C>A,B \\
\hline Afternoon shifts & $24 \cdot 45$ & $24 \cdot 21$ & & 1,268 & $9 \cdot 26^{\star \star}$ & $A>B$ \\
\hline Night shifts & $7 \cdot 32$ & $7 \cdot 33$ & & 1,270 & 0.02 & $\mathrm{~B}, \mathrm{~A}$ \\
\hline Rest days & 24.06 & $24 \cdot 00$ & $24 \cdot 00$ & 2,275 & 0.22 & $\mathrm{~A}, \mathrm{~B}, \mathrm{C}$ \\
\hline
\end{tabular}

STATISTICAL ANALYSES

Given that a specific change was predicted, simple main effects were calculated with multivariate analyses of variance, with age as a covariate. In this way, specific differences according to time, and specific changes within groups over time could be calculated. Only those differences that were found to be significant are reported. Also, a series of $\chi^{2}$ tests were performed to compare high with low scorers on the questionnaire within each of the groups. All these results are reported.

\section{Results}

DIFFERENCES BETWEEN THE GROUPS AT TIME 1 Table 2 shows the mean scores adjusted for age, and the results of the analyses comparing the experimental group, the control three shift group, and the control day group on the sleep, health, and wellbeing measures.

\section{Day v three shift workers}

Day workers reported significantly less social and domestic disruption and significantly less dissatisfaction with their social life than either of the three shift groups. They also reported going to sleep later and sleeping for longer between their day shifts than the three shift workers did between their morning shifts, although this was probably a reflection of the later start time of 0830 compared with 0600 . There were no other significant advantages of day work although inspection of table 2 shows that they scored lower on many of the problem scales. A $\chi^{2}$ test showed a significantly higher incidence of high scorers on the questionnaire in the shift working groups $(35.1 \%)$ than the day working group $(22 \cdot 4 \%)\left(\chi^{2}(1)=\right.$ 3.93, $\mathrm{P}<0.05)$.
Advancing $\mathrm{v}$ delaying three shift workers

There were only five significant differences between the two three shift groups at time 1 . Those on the delaying system (experimental group) reported more satisfaction with their shift system and social life, yet reported less enjoyment at work than the advancing (control three shift) group. Also, they reported going to sleep earlier and having fewer sleep difficulties between afternoon shifts. More detailed analyses of the items that comprised the sleep difficulties scale showed that the delaying group had less difficulty falling asleep $\left.\left(F_{1,281}\right)=16.14, \mathrm{P}<0.001\right)$, and slept better $\left.\left(F_{1,281}\right)=15.11, \mathrm{P}<0.001\right)$ on the afternoon shifts. There was no significant difference in the number of high scorers on the questionnaire between the delaying group $(31 \%)$ and the advancing group (38\%), $\left(\chi_{1}^{2}=1 \cdot 13, \mathrm{P}>\right.$ $0 \cdot 05)$.

CHANGE FROM TIME 1 TO TIME 2

Only those people who had taken part in the study at both time 1 and time 2 were included in this stage of the analyses. Table 3 shows the adjusted means and the results of the analyses. In view of the large number of variables and the associated probability of a type I error, attention was confined within the analyses to the following: firstly, those measures that had shown a significant difference between the experimental and the control three shift groups at time 1; secondly, those measures that had not shown a significant difference between the two groups at time 1, but had shown a significant change over time within the experimental group, but not in the control three shift group.

The experimental group showed a significant increase in sleep difficulties between afternoon shifts, whereas the increase in the control three shift group was not significant. Specific sleep difficulties that increased between afternoon shifts included difficulty in falling asleep $\left(t_{84}=-1.93, \mathrm{P}<0.05\right)$, in getting up $\left(t_{81}=-2.50, \mathrm{P}<0.05\right)$, and in sleeping less well $\left(t_{83}=-2.50, \mathrm{P}<0.05\right)$. There was, however, no significant change in time of sleep onset between afternoon shifts for either of the groups.

The experimental group reported little change in dissatisfaction with their shift system or enjoyment at work, despite significant changes on both of these measures for the control three shift group. That is, the control group reported significantly more dissatisfaction with their shift system, and less enjoyment at work over time. Also, the experimental group did not show any change in dissatisfaction with their social life, although there was a significant decrease in the disruption to social life at time 2 , a variable that had not shown a significant difference between the two groups at time 1 . Other variables that showed a significant change over time for the experimental group, but not for the control group, was the number of cigarettes smoked and the amount of alcohol drunk a week. A significant decrease was noted for the experimental group over time. 
Table 3 Changes in the mean scores within the groups between time 1 and time 2

\begin{tabular}{|c|c|c|c|c|c|c|c|c|c|c|c|c|}
\hline & \multicolumn{4}{|c|}{ Experimental } & \multicolumn{4}{|c|}{ Control three shift } & \multicolumn{4}{|c|}{ Control day } \\
\hline & $T 1$ & $T 2$ & $D f$ & $F$ & $T 1$ & $T 2$ & $D f$ & $F$ & $T 1$ & $T 2$ & $D f$ & $F$ \\
\hline $\begin{array}{l}\text { Psychological health } \\
\text { Chronic fatigue } \\
\text { Gastrointestinal } \\
\text { problems }\end{array}$ & $\begin{array}{r}11 \cdot 38 \\
27 \cdot 71 \\
8 \cdot 85\end{array}$ & $\begin{array}{r}11 \cdot 36 \\
28 \cdot 57 \\
8 \cdot 54\end{array}$ & $\begin{array}{l}1,212 \\
1,191 \\
1,216\end{array}$ & $\begin{array}{l}0.09 \\
0.95 \\
3.26\end{array}$ & $\begin{array}{r}11 \cdot 80 \\
27 \cdot 68 \\
9 \cdot 51\end{array}$ & $\begin{array}{r}12 \cdot 22 \\
29 \cdot 04 \\
9 \cdot 68\end{array}$ & $\begin{array}{l}1,212 \\
1,191 \\
1,216\end{array}$ & $\begin{array}{l}0.91 \\
2.89 \\
0.03\end{array}$ & $\begin{array}{r}10.90 \\
26.55 \\
8.06\end{array}$ & $\begin{array}{r}9 \cdot 60 \\
26 \cdot 82 \\
7 \cdot 09\end{array}$ & $\begin{array}{l}1,212 \\
1,191 \\
1,216\end{array}$ & $\begin{array}{l}1 \cdot 31 \\
0 \cdot 25 \\
4 \cdot 67^{\star}\end{array}$ \\
\hline $\begin{array}{l}\text { Social disruption } \\
\text { Domestic disruption } \\
\text { Non-domestic } \\
\text { disruption }\end{array}$ & $\begin{array}{l}3 \cdot 42 \\
2 \cdot 38\end{array}$ & $\begin{array}{l}3 \cdot 12 \\
2 \cdot 74 \\
2 \cdot 28\end{array}$ & $\begin{array}{l}1,232 \\
1,232 \\
1,227\end{array}$ & $\begin{array}{l}4.01 \star \\
0.72 \\
0.02\end{array}$ & $\begin{array}{l}3 \cdot 72 \\
3 \cdot 08 \\
2 \cdot 48\end{array}$ & $\begin{array}{l}3 \cdot 81 \\
3 \cdot 30 \\
2 \cdot 41\end{array}$ & $\begin{array}{l}1,232 \\
1,232 \\
1,227\end{array}$ & $\begin{array}{l}0.35 \\
1.68 \\
0.06\end{array}$ & $\begin{array}{l}2.06 \\
2.00 \\
1.91\end{array}$ & $\begin{array}{l}1.59 \\
1.72 \\
2.00\end{array}$ & $\begin{array}{l}1,232 \\
1,232 \\
1,227\end{array}$ & $\begin{array}{l}4.09^{\star} \\
1.03 \\
0.57\end{array}$ \\
\hline $\begin{array}{l}\text { Social life dissatisfaction } \\
\text { Sex life dissatisfaction } \\
\text { Job dissatisfaction } \\
\text { Lack of enjoyment at } \\
\text { work }\end{array}$ & $\begin{array}{r}2 \cdot 77 \\
2 \cdot 18 \\
19 \cdot 45 \\
3 \cdot 53\end{array}$ & $\begin{array}{r}2 \cdot 78 \\
2 \cdot 52 \\
20 \cdot 20 \\
3 \cdot 49\end{array}$ & $\begin{array}{l}1,231 \\
1,222 \\
1,210 \\
1,234\end{array}$ & $\begin{array}{l}0.14 \\
9 \cdot 01^{\star \star \star} \\
1.82 \\
0.83\end{array}$ & $\begin{array}{r}3 \cdot 11 \\
2 \cdot 34 \\
18 \cdot 89 \\
3 \cdot 19\end{array}$ & $\begin{array}{r}3 \cdot 20 \\
2 \cdot 54 \\
20 \cdot 28 \\
3 \cdot 41\end{array}$ & $\begin{array}{l}1,231 \\
1,222 \\
1,210 \\
1,234\end{array}$ & $\begin{array}{l}1 \cdot 04 \\
5 \cdot 85^{\star} \\
6 \cdot 17^{\star \star} \\
4 \cdot 07^{\star}\end{array}$ & $\begin{array}{r}2 \cdot 06 \\
2 \cdot 09 \\
17 \cdot 32 \\
3 \cdot 35\end{array}$ & $\begin{array}{r}2 \cdot 24 \\
2 \cdot 59 \\
17 \cdot 91 \\
3 \cdot 44\end{array}$ & $\begin{array}{l}1,231 \\
1,222 \\
1,210 \\
1,234\end{array}$ & $\begin{array}{l}0 \cdot 88 \\
6 \cdot 13^{\star \star} \\
0 \cdot 43 \\
0.60\end{array}$ \\
\hline $\begin{array}{l}\text { Shift system dissatisfaction } \\
\text { Alcohol consumption } \\
\text { Cigarette consumption } \\
\text { Sleep difficulties between: }\end{array}$ & $\begin{array}{r}3 \cdot 02 \\
10 \cdot 59 \\
49 \cdot 28\end{array}$ & $\begin{array}{r}2 \cdot 99 \\
8 \cdot 18 \\
38 \cdot 80\end{array}$ & $\begin{array}{l}1,222 \\
1,220 \\
1,218\end{array}$ & $\begin{array}{l}0 \cdot 00 \\
7 \cdot 76^{\star \star} \\
4 \cdot 23^{\star}\end{array}$ & $\begin{array}{r}3 \cdot 31 \\
9 \cdot 44 \\
43.56\end{array}$ & $\begin{array}{r}3.57 \\
9.86 \\
47 \cdot 67\end{array}$ & $\begin{array}{l}1,222 \\
1,220 \\
1,218\end{array}$ & $\begin{array}{l}6 \cdot 89^{\star \star} \\
0.27 \\
2 \cdot 01\end{array}$ & $\begin{array}{r}1.59 \\
7 \cdot 44 \\
25 \cdot 44\end{array}$ & $\begin{array}{r}1.91 \\
7.84 \\
20.09\end{array}$ & $\begin{array}{l}1,222 \\
1,220 \\
1,218\end{array}$ & $\begin{array}{l}2.06 \\
0.00 \\
0.43\end{array}$ \\
\hline $\begin{array}{l}\text { Morning shifts } \\
\text { Afternoon shifts } \\
\text { Night shifts } \\
\text { Rest days }\end{array}$ & $\begin{array}{r}11 \cdot 36 \\
8 \cdot 93 \\
10 \cdot 29 \\
8 \cdot 63\end{array}$ & $\begin{array}{r}11 \cdot 22 \\
9 \cdot 71 \\
10 \cdot 95 \\
8 \cdot 56\end{array}$ & $\begin{array}{l}1,201 \\
1,190 \\
1,187 \\
1,177\end{array}$ & $\begin{array}{l}0 \cdot 26 \\
3 \cdot 74^{\star} \\
1 \cdot 52 \\
0 \cdot 37\end{array}$ & $\begin{array}{r}10.92 \\
10 \cdot 29 \\
10 \cdot 07 \\
8.93\end{array}$ & $\begin{array}{r}11 \cdot 31 \\
10 \cdot 64 \\
10 \cdot 89 \\
8 \cdot 77\end{array}$ & $\begin{array}{l}1,201 \\
1,190 \\
1,187 \\
1,177\end{array}$ & $\begin{array}{l}3 \cdot 06 \\
1.40 \\
6 \cdot 87^{\star \star} \\
0.20\end{array}$ & $9 \cdot 33$ & $10 \cdot 56$ & 1,201 & $3 \cdot 15$ \\
\hline $\begin{array}{l}\text { Sleep duration between: } \\
\text { Morning shifts } \\
\text { Afternoon shifts } \\
\text { Night shifts } \\
\text { Rest days }\end{array}$ & $\begin{array}{l}5 \cdot 19 \\
8 \cdot 56 \\
7 \cdot 34 \\
9 \cdot 17\end{array}$ & $\begin{array}{l}5 \cdot 98 \\
8 \cdot 34 \\
7 \cdot 14 \\
9 \cdot 01\end{array}$ & $\begin{array}{l}1,191 \\
1,176 \\
1,185 \\
1,166\end{array}$ & $\begin{array}{l}1 \cdot 20 \\
0 \cdot 78 \\
3.96^{\star} \\
0.62\end{array}$ & $\begin{array}{l}5 \cdot 10 \\
8 \cdot 61 \\
7 \cdot 53 \\
9 \cdot 01\end{array}$ & $\begin{array}{l}5 \cdot 91 \\
8 \cdot 29 \\
7 \cdot 25 \\
8 \cdot 95\end{array}$ & $\begin{array}{l}1,191 \\
1,176 \\
1,185 \\
1,166\end{array}$ & $\begin{array}{l}0.49 \\
4 \cdot 89^{\star} \\
9 \cdot 95^{\star \star \star} \\
0 \cdot 14\end{array}$ & $7 \cdot 34$ & $6 \cdot 85$ & 1,191 & $2 \cdot 04$ \\
\hline $\begin{array}{l}\text { Sleep onset times between: } \\
\text { Morning shifts } \\
\text { Afternoon shifts } \\
\text { Night shifts } \\
\text { Rest days }\end{array}$ & $\begin{array}{r}22 \cdot 41 \\
24 \cdot 28 \\
7 \cdot 59 \\
23 \cdot 97\end{array}$ & $\begin{array}{r}22 \cdot 58 \\
24 \cdot 40 \\
7 \cdot 63 \\
24 \cdot 07\end{array}$ & $\begin{array}{l}1,195 \\
1,178 \\
1,186 \\
1,169\end{array}$ & $\begin{array}{l}2 \cdot 80 \\
0.52 \\
0 \cdot 01 \\
0 \cdot 21\end{array}$ & $\begin{array}{r}22 \cdot 46 \\
24 \cdot 64 \\
7 \cdot 53 \\
24 \cdot 12\end{array}$ & $\begin{array}{r}22 \cdot 60 \\
24 \cdot 71 \\
7 \cdot 53 \\
24 \cdot 22\end{array}$ & $\begin{array}{l}1,195 \\
1,178 \\
1,186 \\
1,169\end{array}$ & $\begin{array}{l}2 \cdot 07 \\
0.23 \\
0.00 \\
0.79\end{array}$ & $22 \cdot 91$ & $23 \cdot 28$ & 1,195 & 0.96 \\
\hline
\end{tabular}

${ }^{\star} \mathrm{P}<0.05 ;{ }^{\star \star} \mathrm{P}<0.01 ;{ }^{\star \star \star} \mathrm{P}<0.001$

$\mathrm{T} 1=$ time $1 ; \mathrm{T} 2=$ time 2 .

The number of high scorers on the questionnaire was calculated. Comparing only those who completed the questionnaire at both time 1 and time 2, a similarly moderate decrease in scores over time was evident in both the control three shift group $36.6 \% v$ $33.0 \%)$, and the experimental group $(36.2 \% v$ $28 \cdot 7 \%$ )

Two way analyses of variance were performed on these variables to look at the changes that occurred in the experimental group, compared with the control three shift group over time. Only three significant interactions were produced: social life disruption $\left.\left(F_{1,210}\right)=6.18, \mathrm{P}<0.01\right)$, the control three shift group reported more disruption over time, and the experimental group reported significantly less, the amount of alcohol consumed $\left.\left(F_{1,197}\right)=6.99, P<0.01\right)$, and cigarette consumption $\left.\left(F_{1,195}\right)=7.54, P<0.01\right)$. In each case there was little change in the control group, yet a significant decrease over time in the experimental group. Although there was no overall interaction in disturbances of sleep between afternoon shifts, one of the sleep disturbance items did show a significant interaction, that is, sleeping less well $\left(F_{1,197}\right)=4.85$, $P<0.05)$, the experimental group reported a greater change, specifically, sleeping less well after the change.

\section{Discussion}

Our study examined the impact on health and wellbeing of a change from a delaying to an advancing shift system. Based on the scientific literature it was expected that the advancing system would be more problematic. Consequently, the change that was to take place was not considered to be the best option from the point of view of the workers' health. Comparison of the workers on the advancing and delaying systems before the change took place suggested that advancing shifts might not be as harmful as originally suggested. There were few significant differences between the two groups. The two most prominent related to the severity of sleep difficulties between successive afternoon shifts, and dissatisfaction with their social life. Those on the advancing system reported more problems. In most cases both groups of three shift workers reported more problems than the day shift workers, although these differences were not necessarily significant.

Quite surprisingly, there was little change in many of the measures in any of the three groups over the eight month period. Some of the changes that took place were, however, common to all three groups. For example, all three groups reported a decrease in sleep duration that probably resulted from a seasonal effect. The second test took place in summer and the first test in winter. All three groups reported more dissatisfaction with their sex life at time 2. Such results would suggest that these changes did not occur as a result of the change in shift rotation, as they were common to all three groups.

Of interest was the incidence of high questionnaire scorers in each of the groups. In agreement with earlier results ${ }^{5}$ the incidence within the group of day workers was statistically lower than in either of the groups of shift workers, which might therefore imply a detrimental effect of shift work on psychological health. Of particular interest, although difficult to explain, was the lack of any difference in the number of high scorers between the advancing and the delaying groups at time 1 , and a moderate decrease in the number of cases within both groups over time.

Also of interest was the greater incidence of sleep difficulties between successive afternoon 
shifts for the advancing compared with the delaying group, and the significant increase reported by the delaying group after the change to an advancing system. In particular, difficulties in falling asleep and in sleeping less well were associated with the advancing system. These results are in keeping with earlier ones showing a reduction in sleep disturbances after a change from an advancing to a delaying system, ${ }^{17}$ increased difficulty in falling asleep after an afternoon shift on an advancing system, ${ }^{18}$ and more sleep difficulties between successive afternoon shifts, but not between successive morning or night shifts, on advancing than on delaying systems. ${ }^{19}$ A later time of sleep onset after an afternoon shift on an advancing than on a delaying system has also been shown (similar to our study), ${ }^{17} 18$ even though the later time of sleep onset associated with the experimental group after the change did not reach significance. Thus, it would seem that the direction of shift rotation is important in influencing the quality of sleep between successive afternoon shifts, with advancing systems resulting in more problems. One explanation might be in terms of circadian adaptation to night work; the afternoon shifts now follow a series of night shifts, whereas previously they followed a series of morning shifts. It has been argued that it is easier to delay rather than advance the time of sleep onset-for example, to change from a morning to an afternoon shift than from a night shift to an afternoon shiftbecause of the tendency of the sleep-wake cycle to run with a period $>24$ hours, if allowed to free run. Hence, sleep tends to occur later and later with respect to clock time.

The second main finding was the decrease in social disruption reported by the experimental group after the change, which may reflect the influence of the longer weekend breaks associated with the advancing system, compared with the delaying system. This could possibly account for the ratings of satisfaction with the shift system and enjoyment at work not worsening after the change.

In summary, contrary to the few published studies ${ }^{161719}$ there seems to be little evidence from our study to support the view that advancing as opposed to delaying systems are the most detrimental. There are, however, two possible explanations for this. Firstly, the actual shift system under investigation was discontinuous in nature, with at least two days off between each change of shift, and therefore did not include any quick returns. Consequently, it could be argued that the organisation and sequencing of shifts are not particularly problematic. Secondly, the relatively short time span over which the study was conducted might not be sufficient for the build up of health related problems to occur, although studies conducted over a similar length of time have shown an effect. ${ }^{16}$ In our study the relatively short time engaged in shift work altogether, by either of the three shift groups, might account in part for the small differences in health problems reported between them and the day shift workers.
The main implications of the direction of shift rotation seem to be acute in nature and focus on the detrimental effect of the advancing system on the quality and disturbance of sleep, and the advantageous effect of the two long weekends. It is, however, not possible to say from these results what the long term chronic health effects of this change in shift system might be. Given the relatively small differences between the two groups at time 1, and the results of our earlier work comparing the effects of advancing and delaying shift systems, ${ }^{19}$ it could perhaps be argued that the direction of shift rotation by itself may be less problematic than the presence of a quick return within the schedule. Thus, the discontinuous nature of these shift systems are not particularly problematic for the people concerned; however, the long term implications, if any, of the sleep difficulties associated with the afternoon shift remain unknown.

1 Costa G, Apostoli P, D'Andrea F, Gaffuri E. Gastrointestinal and neurotic disorders in textile shift workers. In: Reinberg A, Vieux N, Andlauer P, eds. Night and shift work: biological and social aspects. Oxford: Pergamon shift work:

2 Rutenfranz J, Haider M, Koller $M$. Occupational health measures for night workers and shiftworkers. In Folkard S, Monk TH, eds. Hours of work: temporal factor in work scheduling. Chichester: Wiley, 1985.

3 Vidacek S, Radosevic-Vidacek B, Kaliterna L. Predictive validity of individual difference measures for sleep problems in shiftworkers: preliminary results. In: Oginski A Pokorski J, Rutenfranz J, eds. Contemporary advances in shiftwork research. Krakow: Medical Academy, 1987.

4 Bohle P, Tilley AJ. The impact of night work on psychological well-being. Ergonomics 1989;32:1089-99.

5 Poole CJM, Evans GR, Spurgeon A, Bridges KW. Effects of a change in shift work on health. Occup Med 1992; 42:193-9.

6 Walker J. Social problems of shiftwork. In: S Folkard, TH Monk, eds. Hours of work: temporal factors in work scheduling. Chichester: Wiley, 1985

7 Monk TH, Folkard S. Making shiftwork tolerable. London: Taylor and Francis, 1992.

8 Uehata T, Sasakawa N. The fatigue and maternity disturbances of night work women. $f$ Hum Ergol Tokyo 1982;11(suppl):465-74.

9 Lavie P, Chillag N, Epstein R, Tzischinsky O, Givon R, Fuchs S, Shahal B. Sleep disturbance in shiftworkers: a marker for maladaptation syndrome. Work and Stress 1989;3:33-40.

10 Akerstedt T. Psychological and psychophysiological effects of shiftwork. Scand $₹$ Work Environ Health 1990;16: 67-73.

11 Estryn-Behar M, Kaminski M, Peigne E, et al. Stress at work and mental health status among female hospital workers. Br F Ind Med 1990;47:20-8.

12 Dirkx J. Adaptation to permanent night work: the number of consecutive work nights and motivated choice. Ergonomics 1993;36:29-36

13 Barton J, Smith L, Totterdell P, Spelten E, Folkard S. Does individual choice determine shift system acceptability? Ergonomics 1993;36:93-100.

14 Czeisler CA, Moore-Ede MC, Coleman RH. Rotating shiftwork schedules that disrupt sleep are improved by applying circadian principles. Science 1982;217:460-3.

15 Wever RA. Man in temporal isolation: basic principles of the circadian system. In: Folkard S, Monk TH, eds. the circadian system. In: Folkard S, Monk TH, eds. Hours of work: temporal

16 Landen RO, Vikstrom AO, Oberg B. Ordningspoliser Stockholm, Delrapport III: I Intervention-sociala och psykologiska reaktioner pa forandrade arbetstider. Rapporter fran Laboratoriet for Klinisk Stressforskning Karolinska Institutet. Stockholm: Karolinska Institutet, 1981. (No 126)

17 Epstein R, Tzischinsky O, Lavie P. Sleep-wake cycle in rotating shift workers: effects of changing from phase advance to phase delay rotation. Paper presented at the 20th international conference on chronobiology. Tel Aviv, Israel: 1991

18 Lavie $P$, Tzischinsky O, Epstein R, Zomer J. Sleep-wake cycle in shift workers on a "clockwise" and "counterclockwise" rotation system. Isr f Med Sci 1992;28: 636-44.

19 Barton J, Folkard S. Advancing versus delaying shift systems. Ergonomics 1993;36:59-64. 
20 Turek F. Circadian principles and design of rotating shift work schedules. Am f Physiol 1986;251:R636-8.

21 Folkard S, Barton J. Does the "forbidden zone" for sleep onset influence morning shift sleep duration? Ergonomics 1993;36:85-92.

22 Lavie P. Ultrashort sleep-waking schedule III. "Gates" and "forbidden zones" for sleep. Electroencephalography

23 Totterdell P, Smith L. Ten-hour days and eight-hour nights: can the Ottawa shift system reduce the problems of shiftwork? Work and Stress 1992;6:139-5

24 Knauth P, Kieswetter E. A change from weekly to quicker shift rotations: a field study of discontinuous 3 shift workers. Ergonomics 1987;30:1311-22.

25 Jansen B, Van Hirtum A, Thierry $H$. The countervalue of rapidly and slowly rotating 5 shift rotas: some initial results. In: A Wedderburn, P Smith, (eds). Psychological approaches to night and shift work. Edinburgh: Heriot Watt University, 1984

26 Akerstedt T, Torsvall L. Experimental changes in shift schedules-their effects on well-being. Ergonomics 1978; 21:849-56.

27 Folkard S, Barton J, Costa G, Smith L, Spelten E, Totterdell P. The standard shiftwork index. Ergonomics 1993;36:313.

28 Barton J, Costa G, Smith L, Spelten E, Totterdell P Folkard S. The standard shiftwork index: a battery of questionnaires for assessing shiftwork related problems. Work and Stress 1994;(in press).

29 Goldberg DP. The detection of psychiatric illness by questionnaire. Oxford: Oxford University Press, 1972.

30 Banks MH, Clegg CW, Jackson PR, Kemp N, Stafford EM, Wall TD. The use of the general health questionnaire as an indicator of mental health in occupational studies. Fournal of Occupational Psychology 1980;53: 187-94.

31 Goldberg DP. Manual of the general health questionnaire. Windsor: Nfer-Nelson, 1978

32 Hackman JR, Oldham GR. Development of the job diagnostic survey. 7 Appl Psychol 1975;60:159-70.

\section{Instructions to authors}

Three copies of all submissions should be sent to: The Editor, Occupational and Environmental Medicine, BMJ Publishing Group, BMA House, Tavistock Square, London WC1H 9JR, UK. All authors should sign the covering letter as evidence of consent to publication. Papers reporting results of studies on human subjects must be accompanied by a statement that the subjects gave written, informed consent and by evidence of approval from the appropriate ethics committee. These papers should conform to the principles outlined in the Declaration of Helsinki (BMF 1964; ii:177).
If requested, authors shall produce the data on which the manuscript is based, for examination by the Editor.

Authors are asked to submit with their manuscript the names and addresses of three people who they consider would be suitable independent reviewers. They will not necessarily be approached to review the paper.

Papers should include a structured abstract of not more than 300 words, under headings of Objectives, Methods, Results, and Conclusions. Please include up to three keywords or key terms to assist with indexing. 